\title{
Mosquito Species Composition And Insecticide Resistance Status of Anopheles Arabiensis In Itang Special Woreda, Gambella, Southwestern Ethiopia
}

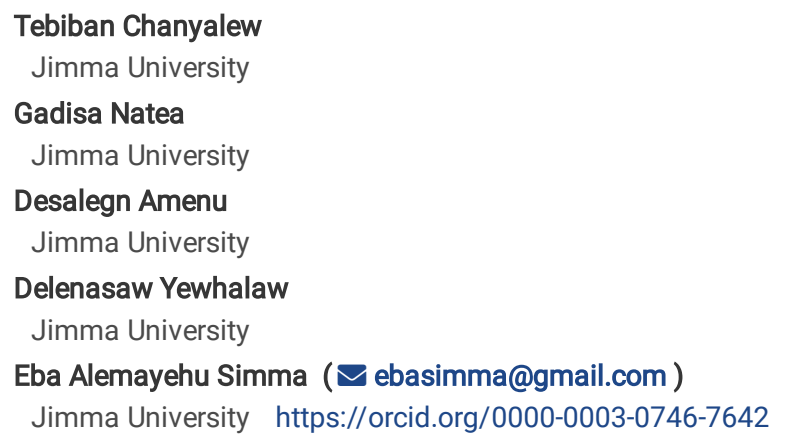

Research

Keywords: malaria, insecticide resistance, Anopheles mosquito, Itang, Ethiopia

Posted Date: December 28th, 2021

DOI: https://doi.org/10.21203/rs.3.rs-1179058/v1

License: (c) (i) This work is licensed under a Creative Commons Attribution 4.0 International License. Read Full License 


\section{Abstract}

Introduction: Anopheles arabiensis, member species of the Anopheles gambiae complex, is the primary vector of malaria widely distributed in Ethiopia. Anopheles funestus, An. pharoensis and An. nili are secondary vectors occurring with limited distribution in the country. Indoor residual spraying (IRS) and long-lasting insecticidal nets (LLINs) are pillars for the interventions against malaria control and elimination efforts in Ethiopia. However, the emergence and widespread of insecticide resistance in the major malaria vector, An. arabiensis, might compromise the efforts of the country. The aim of this study was to investigate composition of mosquito species and insecticide resistance status of An. arabiensis in Itang special woreda (district), Gambella, southwestern Ethiopia.

Materials and methods: Adult mosquitoes were sampled from September 2020 to Feburary 2021 using Centers for Disease Control and Prevention (CDC) light trap and Pyrethrum Spray Catch (PSC). Moreover, mosquito larvae were also collected from different breeding sites and reared to adults to assess susceptibility status of populations of An. gambiae s.I. in the study area. Susceptibility tests were conducted on two to three days old non blood fed female $A n$. gambiae s.I using insecticide impregnated papers with deltamethrin (0.05\%), alpha-cypermethrin (0.05\%), propoxur (0.1\%), pirimiphos-methyl $(0.25 \%)$ and bendiocarb $(0.1 \%)$ following World Health Organization (WHO) standard susceptibility test procedure. Molecular diagnostics were done for the identification of member species of $A n$. gambiae s.l and detection of knockdown resistance ( $k d r)$ allele using species specific polymerase chain reaction (PCR) and allele specific PCR.

Results: In total, 468 adult mosquitoes were collected from different houses. Culex mosquitoes were the most dominant (80.4\%) followed by Anopheles mosquitoes. Three species of Anopheles mosquitoes (An. coustani, An. pharoensis, and An. gambiae (s.l.)) were identified, of which An. coustani was the dominant (8.1\%) species. WHO bioassay tests revealed that the populations of An. gambiae s.l in the study area are resistant against alpha-cypermethrin and deltamethrin whereas, susceptible to bendiocarb, pirimiphos-methyl and propoxur. Out of the total 86 An. gambiae s.I specimens assayed, 79 (92\%) successfully amplified and identified as An. arabiensis. West African Kdr (L1014F) mutation was detected with high Kdr allele frequency ranging from 67$88 \%$.

Conclusion: The detection of target site mutation, $k d r$ L1014F allele, coupled with the phenotypic resistance against alpha-cypermethrin and deltamethrin call for continuous resistance monitoring.

\section{Background}

Malaria is vector-borne disease caused by five Plasmodium species namely; Plasmodium falciparum, P. ovale, P. malariae, P. vivax and P. knowlesi. The parasite transmitted to human through the bite of infective female Anopheles mosquito [1]. There are over 445 recognized species of Anopheles mosquito of which around 70 species are potential malaria vectors [2]. In Africa, the major malaria vectors are Anopheles gambiae and An. funestus species complexes, but there are also a number of primary and secondary vectors that contribute to the malaria transmission [2].

In Ethiopia, there are more than 45 documented Anopheles mosquito species [3], of which only four species are malaria vectors. Anopheles arabiensis, member species of the An. gambiae complex, is the primary vector of malaria widely distributed in the country[4, 5]. Anopheles funestus An. pharoensis and An. nili are secondary vectors occurring with varying population densities, limited distribution and vector competence [6]. Very recently, an invasive Anopheles species, An. stephensi, has been documented in the country [7] which might complicate the malaria elimination effort of the country [8].

Chemical based vector control intervention is the pillar strategy to combat malaria. Indoor residual spraying (IRS) and long-lasting insecticidal nets (LLINs) are instrumental for the significant reduction of malaria morbidity and mortality [9]. However, the emergence and widespread of insecticide resistance in the major malaria vectors particularly in Africa might compromise effectiveness of chemical based (IRS and LLINs) interventions against malaria control and elimination efforts [9-15].

Insecticide resistance has been reported in more than 500 insect species worldwide among which over 70 Anopheles species (Diptera: Culicidae) are responsible for the transmission of malaria parasites to humans (Hemingway and Hilary, 2000). Insecticide resistance has become a serious challenge for the control and elimination of malaria due to the fact that malaria vectors are resistant to the four commonly used insecticide classes (pyrethroids, organochlorines, carbamates and organophosphates) [9, 15]. In Ethiopia, DDT resistance by An. arabiensis was reported in the 1990s, since then widespread DDT resistance was documented throughout the country [10,11,17-19]. Moreover, resistance against other classes of insecticides such as carbamates (bendiocarb), organophosphates (malathion) and pyrethroids (permethrin, deltamethrin) has been reported from various regions of the country $[19,20]$

In the last decade the number of malaria cases has declined due to a high coverage of IRS and scaling up of LLINs [9, 15]. This result initiated the national malaria control and elimination program of Ethiopia to develop national malaria elimination road map to eliminate malaria from the country by 2030 [21]. However, this plan might be compromised as the magnitude of resistance against several insecticides is increasing in the An. arabiensis populations [9, $19,20]$.

Insecticide resistance largely caused by two major mechanisms. The first one is due to target-site insensitivity as a result of mutations in the target site of the insecticide that changes binding. The second mechanism is metabolic based resistance, where the insecticide is either degraded, sequestered or transported/excreted out of the cell before binding to the target site [22, 23]. 
Target-site and metabolic based resistance mechanisms operating in malaria vectors in several malaria endemic African countries have been documented. Knockdown resistance $(k d r)$ is target site mutations in the voltage-gated sodium channel gene of mosquito nerve membranes is associated with DDT and pyrethroids resistance. In Anopheles, this involves the substitution of leucine (TTA) to phenylalanine (TTT) (kdr.1014F) or to serine (TCA) ( $k d r L 1014 S)$ [24, 25]. In addition, substitution of asparagine to tyrosine (N1575Y) is linked with resistance in An. gambiae s.s [26] but not in An. arabiensis [19]. There is also an acetylcholinesterase gene (ace-1R) mutation, substitution of glycine (GGC) to a serine (AGC) which confers resistance to organophosphates and carbamates [27]. In Ethiopia, target site resistance mechanism, Kdr L1014F (West Africa Kdr), in populations of An. arabiensis documented in several populations across the country $[10,11,17,19,20]$. Metabolic based resistance in Anopheles mosquitoes have been reported from several countries in Africa [28-31]. Moreover, modifications in the cuticle either through cuticle thickening and/or altering of the cuticle composition of arthropods which can slow down the penetration of chemical compounds [32-34] has also been reported in Anopheles populations [35].

Approximately $60 \%$ of the Ethiopian populations live in malaria risk areas [6]. The disease primarily occurs up to the 2000 -meter ( $\mathrm{m}$ ) elevation but can also occasionally affect areas over $2000 \mathrm{~m}$ elevation in response to the spatial and temporal changes [36, 37]. Malaria transmission is unstable and seasonal which produces little immunity in the community; hence malaria epidemics are common and lead to high mortality and morbidity [6]. Gambella is one of the malarious areas of Ethiopia with high malarial endemicity. Itang special woreda is known for its a stable form of malaria transmission [38]. Despite the current effort of the country, malaria incidence rate in Itang did not decline unlike many other malarious areas of Ethiopia. [39]. Moreover, to the best of our knowledge composition of mosquito species and insecticide resistance status of Anopheles gambiae s.l in Itang, not yet studied, and the resistance mechanisms operating in the populations not known. Therefore, this study aimed to investigate mosquito species composition, insecticide resistance status of Anopheles gambiae s.I and detection of target site mutations associated with DDT and pyrethroid resistance.

\section{Methods And Materials Study area and mosquito collections}

Gambella is administrative regional state located in south western Ethiopia $777 \mathrm{~km}$ away from Addis Ababa (Fig. 1). Most of the region is flat, hot, and humid, with an altitude range of $300-2,300 \mathrm{~m}$ above sea level and sloping westward. The annual average temperature of the region is $21.1^{\circ} \mathrm{C}-35.9^{\circ} \mathrm{C}$, with an average annual rainfall of $600 \mathrm{~mm}$. The region has a total area of 25,802 $\mathrm{km}^{2}$ and administratively divided into three Zones (Nuwer, Agnua, Mezeng) and one special woreda, Itang [40]. According to the 2017 Ethiopian population projection, Gambella is sparsely populated with the total population approximately $436,000[41]$.

The study was conducted from September 2020-Feburary 2021 in Itang special woreda, which is situated $42 \mathrm{~km}$ to the west of the regional capital of Gambella. Itang has 23 kebeles, with estimated total population of 45,772 and 9,154 households [41]. The woreda's average annual temperature and rainfall are $29^{\circ} \mathrm{C}$ and $1,000 \mathrm{~mm}$, respectively. The climatic conditions of the woreda are favorable for the existence of a stable form of malaria throughout the year [6]

Potential mosquito breeding habitats (Baro river fringes, paddle or farming field ditches, sewerage, and stagnant water pools) were first inspected for the presence of mosquito larvae and positive habitats were sampled with a $350 \mathrm{ml}$ capacity mosquito scoop. Dipping was done following WHO guidelines and standard operating procedures for entomological surveillances [42]. Anopheline mosquito larvae were sampled from breeding sites, and kept in a room at constant $80 \% \pm 10 \% \mathrm{RH}$ and $27 \pm 2^{\circ} \mathrm{C}$. The larvae were fed baking powder. The pupae were sorted and transferred to beakers and placed inside a cage adults to emerge. Adults were provided $10 \%$ sugar in the cage and, 2-3 days old female mosquitoes were used for insecticide susceptibility tests.

Adult Anopheles mosquitoes were collected using CDC light traps and Pyrethrum Spray Catch (PSC) from selected houses in study area. CDC light traps were placed in three selected houses indoor and outdoor from 6:00PM to 06:00AM to collect female Anopheles mosquitoes for two consecutive days per month from September 2020 to February2021. In addition to CDC light traps, indoor resting mosquitoes were collected using PSC in ten selected houses from 6:00AM to 9:00AM once in a month from October 2020 to February 2021. Before spray the whole house was covered by white sheet and closed every opening such as windows, door, and others. After fifteen minute of spraying knockdown mosquitoes were collected and recorded and separately placed in Eppendorf tube. Anopheles mosquitoes were morphologically identified to the species using taxonomic keys [43, 44].

\section{Insecticide susceptibility test}

Two to three days old non blood fed adult females morphologically identified as An. gambiaes s.l were exposed to insecticide impregnated papers with discriminating doses of deltamethrin ( $0.05 \%)$, alpha-cypermethrin $(0.05 \%)$ propoxur $(0.1 \%)$ pirimiphos-methyl $(0.25 \%)$, bendiocarb $(0.1 \%)$ and control papers impregnated with oil. Insecticides were selected based on their current operational significance in the national malaria control program. Pirimiphosmethyl, propoxur and bendiocarb are currently used for IRS in Ethiopia and pyrethroid is incorporated in LLINs. The insecticide impregnated and control papers were obtained from the WHO collaboration Centre, Vector Control Research Unit, School of Biological Sciences, Penang, Malaysia. The insecticides were first tested on susceptible strain An. arabiensis collected from Jimma University Tropical and Infectious Disease Research Center insectary to assure the quality of the impregnated papers. Then, the susceptibility test was carried out on nonblood fed female mosquitoes collected and reared from the study area. Batches of 25 mosquitoes in four replicates were exposed in test kit tubes with insecticide impregnated papers and a control in two replicates, each with equal number of mosquitoes, exposed to papers impregnated with silicone oil was run in parallel for all bioassays for one hour. Knockdown were recorded at 10, 15, 20, 30, 40, 50, and 60 minutes [45]. After one hour, mosquitoes were transferred into holding tubes and provided with $10 \%$ sucrose solution with soaked cotton pads. Mortality was recorded 24 hour post exposure. Mosquitoes, both dead and alive, were individually preserved in Eppendorf tubes over silica-gel for further molecular assays. The same numbers of mosquitoes were exposed to insecticide free papers as controls.

Page 3/10 
DNA extraction of An. gambiae s.I

Genomic DNA of individual Anopheles mosquito was extracted from 75 survived and 11dead mosquitoes (sampled from mosquitoes exposed to alphacypermethrin and deltamethrin) using DNAzol reagent (MRCgene, USA) with minor modification of the protocol [46].

Molecular identification of An. gambiae s.I

Morphologically identified Anopheles gambiae s.I female mosquitoes (alpha-cypermethrin and deltamethrin survived and dead mosquitoes) were selected for the molecular identification of members of An. gambiaes.I species using species specific polymerase chain reaction (PCR) at Molecular Biology Laboratory, Tropical and Infectious Diseases Research Centre (TIDRC), Sekoru, Jimma University. An. arabiensis susceptible colony strain was used as a positive control. The PCR assay was done adapting the established protocol [47]. Finally, the band size of PCR products for each species was visualized on a $2 \%$ agarose gel.

\section{Detection of LF14F ( Kdr allele)}

Allele specific PCR assay was conducted on the same specimens used for the identification of member species of An. gambiae s.I. as indicated under 3.5 above. The presence of West Africa Kdr (L1014F) mutation was detected adapting the established protocol [24]. Finally, the band size of the PCR products for $k d r$ allele was visualized on a $2 \%$ agarose gel to determine the genotype to homozygous resistant (RR), heterozygous resistant (RS) and susceptible or wild type (SS) Kdrallele.

\section{Data analysis}

Susceptibility status data was analyzed based on the WHO 2016 classification criteria. As per the criteria 24 hour mortality rate $98 \%$ and above considered fully susceptible; between 90 and $98 \%$, possible resistance or suspected resistance; and mortality below $90 \%$ classified as resistant. When the control mortality was between 5 and $20 \%$, the average observed mortality was corrected using Abbott's formula [48]. When the control mortality was above 20\% the test result was discarded and the test was repeated.

\section{Results}

\section{Mosquito densities and species composition}

In total, 468 mosquitoes were collected using CDC light trap and PSC collection methods from different houses (Table 1). The majority of mosquitoes were Culex spp. (80.4\%) followed by Anopheles mosquitoes. Three species of Anopheles mosquitoes such as An. coustani, An. pharoensis, and An. gambiae s.I were identified, of which An. coustani was dominant among others $(8.1 \%$; $=38)$ (Table 1$)$. As shown in Table 1 the higher number of mosquito was collected outdoor by CDC light traps.

Table 1

Species composition and abundance of mosquitoes in Itang Special Woreda, southwestern Ethiopia from September 2020 to February 2021

\begin{tabular}{|lllllllll|}
\hline Mosquito Species & \multicolumn{2}{l}{ Light trap } & \multicolumn{3}{c|}{ PSC } & \multicolumn{3}{c|}{ Total } \\
\cline { 2 - 10 } & Indoor & $\mathbf{( \% )}$ & Out door & $\mathbf{( \% )}$ & & $(\%)$ & & (\%) \\
\hline An. Coustani & 10 & 5.4 & 26 & 11.2 & 2 & 3.9 & 38 & 8.1 \\
\hline An. Pharoensis & 8 & 4.3 & 24 & 10.4 & 3 & 5.9 & 35 & 7.5 \\
\hline An. gambiaes.I & 9 & 4.8 & 8 & 3.5 & 2 & 3.9 & 19 & 4 \\
\hline Culex spp & 159 & 85.5 & 173 & 74.9 & 44 & 86.3 & 376 & 80.4 \\
\hline Total & 186 & 100 & 231 & 100 & 51 & 100 & 468 & 100 \\
\hline
\end{tabular}

Insecticide resistance status of An. gambiae s.I against different insecticides

As per WHO criterion, the local mosquito populations of An. gambiae s.l. were resistant to two groups of pyrethroid insecticides (deltamethrin and alphacypermethrin). Mortality rates of An. gambiaes.l. against deltamethrin and alpha-cypermethrin was $58 \%$ and $42 \%$, respectively. However, the populations of An. gambiaes.l. were completely susceptible to pirimiphos-methyl, propoxur and bendiocarb, where $100 \%$ mortality rate was recorded for the three insecticides (Table 2). 
Table 2

Insecticide susceptibility status of An. gambiae s./populations from Itang special woreda, southwestern Ethiopia, from September 2020 to February 2021

\begin{tabular}{|llllll|}
\hline \multirow{2}{*}{ S.N } & Insecticide & \multicolumn{2}{c}{ An. gambiae s.I tested } & \multicolumn{2}{c|}{ Phenotypic resistance } \\
\cline { 3 - 5 } & & No. tested & No. dead & $\%$ mortality & \\
\hline 1 & Alpha-cypermethrin (0.05\%) & 100 & 42 & $42 \%$ & Resistant \\
\hline 2 & Deltamethrin (0.05\%) & 100 & 58 & $58 \%$ & Resistant \\
\hline 3 & Propoxur (0.1\%) & 100 & 100 & $100 \%$ & Susceptible \\
\hline 4 & Bendiocarb (0.1\%) & 100 & 100 & $100 \%$ & Susceptible \\
\hline 5 & Pirimiphos-methyl (0.25\%) & 100 & 100 & $100 \%$ & Susceptible \\
\hline
\end{tabular}

\section{Molecular identification of An. gambiae s.I and detection of L1014F Kdr allele}

Out of the total 86 An. gambiae s.I specimen assayed using species specific PCR, 79 (92\%) of the specimens were successfully amplified and all were identified as An. arabiensis. The allele specific PCR revealed the presence of the knock-down resistance $(k d r)$ L1014F allele with 92.7\% ( $n=51)$ homozygous and $7.3 \%(n=4)$ heterozygous $k d r$ resistance allele respectively with the $K d r$ allele frequency ranging from $67-88 \%$ (Table 3 ).

Table 3

Genotypic and $k d r$ allele frequency in populations of An. arabiensis from Itang special woreda, southwestern Ethiopia, from September 2020 to February 2021

\begin{tabular}{|lllll|}
\hline Insecticide & Number assayed & Bioassay phenotype & Genotype & Allele frequency \\
\cline { 3 - 5 } & & & SS RS RR & R S \\
\hline Deltamethrin & 34 & Survived & 5416 & 7228 \\
\cline { 2 - 4 } & 6 & Dead & $1-2$ & 6733 \\
\hline Alpha-cypermethrin & 41 & Survived & $4-30$ & 8812 \\
\cline { 2 - 3 } & 5 & Dead & $1-3$ & 7525 \\
\hline Note: RR-Homozygous resistant, RS-Heterozygous resistant and SS-homozygous susceptible, R-resistant, S-wild type \\
\hline
\end{tabular}

\section{Discussion}

Anopheles coustani, An. pharoensis and An. gambiaes.I. were the three species identified from Itang, southwestern Ethiopia. Of all Anopheles mosquitoes, An. coustani was the most prominent species followed by An. pharoensis and An. gambiae s.I. In the study site the abundance of mosquito species collected by CDC light trap was higher outdoor than indoor. Unlike many other localities in Ethiopia [49-51], the abundance of An. coustani dominated An. gambiae s.I. A study from Lare, Gambella documented higher density of An. gambiae s./ than An. coustani [50] contrasting the result of the current study. This difference might be due to sampling period difference which leads to variation or shifts in density for various species of mosquitoes. Taye and his coworkers sampled mosquitoes from May to September 2017 whereas in our study sampling time was between September and February. Moreover, the difference might also be due to the type of breeding habitat. The breeding site where the Anopheles mosquitoes sampled was shore to the Baro River and due to this reason the breeding sites were covered by plants and shaded the water which might be favorable for An. coustani [52]. Very recently, higher density of An. coustani than An. gambiae s.I populations were reported from non-irrigated swampy and river edges in Arjo Didessa, South west Ethiopia [53]. Unlike An. coustani, An. gambiae s.I. typically breeds in small, clear, sunlit temporary water pools [54] where vegetative cover is low [52, 55]. In Ethiopia the role of An. coustani was not clearly studied but very recently it was found being infected with Plasmodium species [56] showing evidence for the malaria transmission in the country. Therefore, the high abundance of An. coustani in Itang might call attention to further study its role in malaria transmission $[57,58]$

The molecular identification of member species of An. gambiaes.I confirmed that An. arabiensis is the only member species found in the study area. This finding is similar to previously reported studies from other parts of Ethiopia $[10,17,19,20]$. Anopheles arabiensis populations from the study area were found highly resistant to deltamethrin like other populations of An. arabiensis from different localities [10, 19, 20] Sudan [59] and Uganda [60]. The current study also showed that An. arabiensis populations were resistance to alpha-cypermethrin. Similarly, studies from South-West Ethiopia [61] and Congo [62] reported very high resistance to pyrethroids but susceptible to bendiocarb, propoxur and pirimiphos-methyl. In contrary, populations of An. arabinesis form Malawi were found susceptible to alpha-cypermethrin [63].

The population of An. arabiensis collected from Itang found fully susceptible to bendiocarb and propoxur. This report is in agreement with other studies from different regions in Ethiopia [11, 19], Sudan [59], Yemen [64], Burkina Faso and Chad [65]. However, unlike the current finding resistance against bendiocarb has been developed by An. arabiensis populations in some other parts of Ethiopia [17, 20]. The current result is similar to previously reported studies from different parts of Ethiopia where propoxur fully killed An. gambiae s.I [11, 66, 67] Sudan [59]. However, in some other parts of Ethiopia 
resistance against propoxur has been observed $[19,20]$. Similar to propoxur and bendiocarb the An. arabiensis populations from the study area were found susceptible to pirimiphos-methyl. This is similar with studies from different parts of Ethiopia [11, 19], Uganda [68] and Congo [62].

In this study, the population of An. arabiensis were screened for West African kdrallele (L1014F). A very high frequency of the West African $k d$ rallele (L1014F), was observed with $k d r$ allele frequency ranging from 67-88\% indicating that the target site resistance mechanism (Kdr) might contributed for the observed high level of pyrethriod (deltamethrin and alpha-cypermethrin) resistance in the population. This is similar with populations of An. arabiensis in some other areas of Ethiopia [11, 17, 19, 20]. The mutation, L1014F, is widespread in West and West Central Africa [69, 70] also becoming common in East African countries including Sudan [71]; Tanzania [72, 73] and Kenya [74, 75]. The L1014F kdrmutation in the voltage gated sodium channel is a target point mutation against pyrethroids and DDT $[25,76]$ which might occurred by natural selection or by the use long and extensive use of DDT and pyrethroids for ITNs.

LLINs and IRS are the two most widely implemented malaria vector control interventions, and have resulted in a significant reduction of malaria-related mortality and morbidity in Ethiopia $[9,39,77]$. Universal access and coverage of LLINs by all household members regardless of age or gender [78] is not yet achieved in Ethiopia [78-80].

\section{Conclusion And Recommendation}

Overall, this study demonstrated that An. coustani was the predominant Anopheles species recorded among adult Anopheles mosquito collected during the study period in the study area. The high abundance of the species in the study area might call attention to further study the species for its role in malaria transmission. It also revealed that An. arabiensis, a member of An. gambiae complex, has developed high level of resistance against deltamethrin and alpha-cypermethrin. Moreover, target site mutation L1014F kdrallele with high frequency was detected in the populations.

For the success of malaria elimination from Ethiopia by 2030 [6], it is important to control the malaria vectors and focus on successful treatment. Therefore, understanding the type and density of malaria vector species in specific localities, their feeding behavior and interaction with humans is crucial for effective malaria vector control strategies. Moreover, evidence based insecticide susceptibility status of the malaria vector populations and understanding mechanisms of resistance operating in the populations is key for effective insecticide resistance management.

\section{Abbreviations}

CCEs: Carboxylcholinesterases

CDC: Center for Diseases Control and Prevention

CSA: Central Statistics Authority

DDT: Dichlorodiphenyltrichloroethane

DNA: Deoxyribonucleic Acid

FMoH: Federal Minister of Health

GSTs: Glutathione S-transferases

ITNs: insecticide treated nets

Kdr. Knock down resistance

KM: kilometer

LLINs: Long-Lasting Insecticide Treated Nets

MSF: Medicines sans frontiers

OCs: Organochlorines

Ops: Organophosphates

P450s: Cytochrome-P450 monooxygenase

PSC: Pyrethrum Spray Catches

PY: Pyrethroids

SPSS: Statistical package for the social sciences

VGSC: Voltage gated sodium channel 
WHO: World Health Organization

\section{Declarations}

\section{Ethics approval and consent to participate}

Ethical approval letter (Ref. No. RPG/ 056/2020) was obtained from research and ethical review board of College of Natural Sciences, Jimma University, Ethiopia.

\section{Consent for publication}

Not applicable

\section{Availability of data and materials}

Data used for this study are included in the manuscript.

\section{Competing interests}

The authors declare that they have no competing interests.

\section{Funding}

This work was supported by Tropical and Infectious Disease Research Center (TIDRC), Jimma University, Ethiopia.

\section{Authors' contributions}

TC, DY and EA conceived and designed the study. TC performed the field and laboratory experiments and analyzed data and drafted the manuscript. GN drafted the manuscript. DA developed the map of the study site. DY and EA analyzed and interpreted and critically reviewed the manuscript. All authors read and approved the final manuscript.

\section{Acknowledgement}

The authors would like to thank Department of Biology, Tropical and Infectious Disease Research Center (TIDRC) and technical staff members of TIDRC, Jimma University, Ethiopia.

\section{References}

1. Cox FE. History of the discovery of the malaria. Parasit Vectors. 2010;3:1-9.

2. Sinka ME, MJB, Manguin S, Rubio-Palis Y, Coetzee TC, Mbogo M, Janet Hemingway CM, An and Patil P, Temperley WH, Gething, Peter W, Caroline W, Kabaria, Thomas R Burkot REH and SIH. A global map of dominant malaria vectors. Parasit Vectors. 2012;5.

3. Gaffigan TV, Wilkerson RC, Pecor JE, Stoffer JA, Anderson T. Systematic Catalog of Culicidae. Walter Reed Biosystematics Unit, Division of Ecology, Walter Reed Army institute of Research, Silver Spring. Accessed on: 3/22/2021 From http://www.mosquitocatalog.org. 2018.

4. Lulu M, Hadis M, Makonnen Y, Asfaw T. Inversion polymorphisms on anopheles arabiensis chromosomes from several regions of ethiopia. Insect Sci its Appl. 1999;19:207-10.

5. Abose T, Ye-ebiyo Y, Olana D, Alamirew D, Beyene YRL. Re-orientation and definition of the role of malaria vector control in Ethiopia. WHO/MAL/981085 World Heal Organ; 1998.

6. Guidelines FMoHNMalaria, Fourth edition. 2017;1-108. Available from: https://www.humanitarianresponse.info/sites/www.humanitarianresponse.info/files/documents/files/eth_national_malaria_guidline_4th_edition.pdf.

7. Carter TE, Yared S, Gebresilassie A, Bonnell V, Damodaran L, Lopez K, et al. First detection of Anopheles stephensi Liston, 1901 (Diptera: culicidae) in Ethiopia using molecular and morphological approaches. Acta Trop 2018;188:180-6. Available from:

https://doi.org/10.1016/j.actatropica.2018.09.001.

8. Balkew M, Mumba P, Yohannes G, Abiy E, Getachew D, Yared S, et al. An update on the distribution, bionomics, and insecticide susceptibility of Anopheles stephensi in Ethiopia, 2018-2020. Malar J 2021;20:1-13. Available from: https://doi.org/10.1186/s12936-021-03801-3.

9. WHO. World Malaria Report 2020 [Internet]. Who. 2020. Available from: https://www.who.int/teams/global-malaria-programme/reports/worldmalaria-report-2020.

10. Yewhalaw D, Van Bortel W, Denis L, Coosemans M, Duchateau L, Speybroeck N. First evidence of high knockdown resistance frequency in Anopheles arabiensis (Diptera: Culicidae) from Ethiopia. Am J Trop Med Hyg. 2010;83:122-5.

11. Yewhalaw D, Wassie F, Steurbaut W, Spanoghe P, van Bortel W, Denis L, et al. Multiple Insecticide Resistance: An Impediment to Insecticide-Based Malaria Vector Control Program. PLoS One 2011;6.

12. Nkya TE, Akhouayri I, Poupardin R, Batengana B, Mosha F, Magesa S, et al. Insecticide resistance mechanisms associated with different environments in the malaria vector Anopheles gambiae: A case study in Tanzania. Malar J. 2014;13:1-15.

Page $7 / 10$ 
13. Mulamba C, Riveron JM, Ibrahim SS, Irving H, Barnes KG, Mukwaya LG, et al. Widespread pyrethroid and DDT resistance in the major malaria vector anopheles funestus in East Africa is driven by metabolic resistance mechanisms. PLoS One. 2014;9:1-10.

14. Chanda E, Hemingway J, Kleinschmidt I, Rehman AM, Ramdeen V, Phiri FN, et al. Insecticide resistance and the future of malaria control in Zambia. PLoS One. 2011;6:1-9.

15. Bhatt S, Weiss DJ, Cameron E, Bisanzio D, Mappin B, Dalrymple U, et al. The effect of malaria control on Plasmodium falciparum in Africa between 2000 and 2015. Nature. 2015;526:207-11.

16. Hemingway J, Hilary R. Insecticide resistance in insect vectors of human disease. Annu Rev Entomol. 2000; 45:371-91. Available from: https://doi.org/10.1146/annurev.ento.45.1.371.

17. Balkew M, Ibrahim M, Koekemoer LL, Brooke BD, Engers H, Aseffa A, et al. Insecticide resistance in Anopheles arabiensis (Diptera: Culicidae) from villages in central, northern and south west Ethiopia and detection of kdr mutation. Parasit Vectors. 2010;3:2-7.

18. Yewhalaw D, Asale A, Tushune K, Getachew Y, Duchateau L, Speybroeck N. Bio-efficacy of selected long-lasting insecticidal nets against pyrethroid resistant Anopheles arabiensis from South-Western Ethiopia. Parasite Vectors. 2012;5:1-9.

19. Alemayehu E, Asale A, Eba K, Getahun K, Tushune K, Bryon A, et al. Mapping insecticide resistance and characterization of resistance mechanisms in Anopheles arabiensis (Diptera: Culicidae) in Ethiopia. Parasite Vectors. 2017;10:1-11.

20. Messenger LA, Shililu J, Irish SR, Anshebo GY, Tesfaye AG, Ye-Ebiyo Y, et al. Insecticide resistance in Anopheles arabiensis from Ethiopia (2012-2016): A nationwide study for insecticide resistance monitoring. Malar J. 2017;16:1-14.

21. FMoH. Malaria Operational Plan FY. 2016. Pres 'S Malar Initiat Ethiop. 2016;1-76.

22. Liu N. Insecticide resistance in mosquitoes: Impact, mechanisms, and research directions. Annu Rev Entomol. 2015;60:537-59.

23. Feyereisen R, Dermauw W, Van Leeuwen T. Genotype to phenotype, the molecular and physiological dimensions of resistance in arthropods. Pestic Biochem Physiol. 2015;121:61-77. Available from: http://dx.doi.org/10.1016/j.pestbp.2015.01.004.

24. Martinez-Torres D, Chandre F, Williamson MS, Darriet F, Bergé JB, Devonshire AL, et al. Molecular characterization of pyrethroid knockdown resistance $(\mathrm{kdr})$ in the major malaria vector Anopheles gambiae s.s. Insect Mol Biol. 1998;7:179-84.

25. Ranson H, Jensen B, Vulule JM, Wang X, Hemingway J, Collins FH. Identification of a point mutation in the voltage-gated sodium channel gene of Kenyan Anopheles gambiae associated with resistance to DDT and pyrethroids. Insect Mol Biol. 2000;9:491-7.

26. Jones $\mathrm{CM}$, Liyanapathirana M, Agossa FR, Weetman D, Ranson H, Donnelly MJ, et al. Footprints of positive selection associated with a mutation (N1575Y) in the voltage-gated sodium channel of Anopheles gambiae. Proc Natl Acad Sci U S A. 2012;109:6614-9.

27. Weill M, Malcolm C, Chandre F, Mogensen K, Berthomieu A, Marquine M, et al. The unique mutation in ace-1 giving high insecticide resistance is easily detectable in mosquito vectors. Insect Mol Biol. 2004;13:1-7.

28. Vulule JM, Beach RF, Atieli FK, Mcallister JC, Brogdon WG, Roberts JM, et al. Elevated oxidase and esterase levels associated with permethrin tolerance in Anopheles gambiae from Kenyan villages using permethrin-impregnated nets. Med Vet Entomol. 1999;13:239-44.

29. Matowo J, Kulkarni MA, Mosha FW, Oxborough RM, Kitau JA, Tenu F, et al. Biochemical basis of permethrin resistance in Anopheles arabiensis from Lower Moshi, north-eastern Tanzania. Malar J. 2010;9:1-9.

30. Edi CV, Djogbénou L, Jenkins AM, Regna K, Muskavitch MAT, Poupardin R, et al. CYP6 P450 Enzymes and ACE-1 Duplication Produce Extreme and Multiple Insecticide Resistance in the Malaria Mosquito Anopheles gambiae. PLoS Genet. 2014;10.

31. Ibrahim SS, Riveron JM, Stott R, Irving H, Wondji CS. The cytochrome P450 CYP6P4 is responsible for the high pyrethroid resistance in knockdown resistance-free Anopheles arabiensis. Insect Biochem Mol Biol [Internet]. Elsevier Ltd; 2016;68:23-32. Available from: http://dx.doi.org/10.1016/j.ibmb.2015.10.015.

32. Balabanidou V, Grigoraki L, Vontas J. Insect cuticle: a critical determinant of insecticide resistance. Curr Opin Insect Sci. 2018;27:68-74.

33. Balabanidou V, Kampouraki A, Maclean M, Blomquist GJ, Tittiger C, Juárez MP, et al. Cytochrome P450 associated with insecticide resistance catalyzes cuticular hydrocarbon production in Anopheles gambiae. Proc Natl Acad Sci U S A. 2016;113:9268-73.

34. Balabanidou V, Kefi M, Aivaliotis M, Koidou V, Girotti JR, Mijailovsky SJ, et al. Mosquitoes cloak their legs to resist insecticides. Proc R Soc B Biol Sci. 2019;286.

35. Simma EA, Dermauw W, Balabanidou V, Snoeck S, Bryon A, Clark RM, et al. Genome-wide gene expression profiling reveals that cuticle alterations and P450 detoxification are associated with deltamethrin and DDT resistance in Anopheles arabiensis populations from Ethiopia. Pest Manag Sci. 2019;75:1808-18.

36. Lyon B, Dinku T, Raman A, Thomson MC. Temperature suitability for malaria climbing the Ethiopian Highlands. Environ Res Lett. $2017 ; 12$.

37. Haile M, Lemma H, Weldu Y. Population movement as a risk factor for malaria infection in high-altitude villages of Tahtay-Maychew District, Tigray, Northern Ethiopia: A case-control study. Am J Trop Med Hyg. 2017;97:726-32.

38. FMoH. An Epidemiological Profile of Malaria in Mali. Program Natl Lutte contre le Palud. 2014;1-88. Available from: http://www.informmalaria.org/wp-content/uploads/2015/03/Mali-Malaria-Epi-Profile-Report_030315.pdf.

39. Taffese HS, Hemming-Schroeder E, Koepfli C, Tesfaye G, Lee MC, Kazura J, et al. Malaria epidemiology and interventions in Ethiopia from 2001 to 2016. Infect Dis Poverty. 2018;7:1-9.

40. Demeke D. LM. and BJ. Trend of Tuberculosis and Treatment Outcomes in Gambella Region with Special Emphasize on Gambella Regional Hospital, Western Ethiopia. Mycobact Dis. 2013;03. 
41. CSA. Population Projection of Ethiopia for All Regions, Wereda Level from 2014-2017; Central Statistical Agency. 2018.

42. WHO. Entomological field techniques for malaria control. Part I, Learners guide. Geneva, World Health Organization; 1992.

43. M.T.Gillies and Coetzee M. A supplement to the Anophelinae of Africa South of the Sahara. South African Inst Med Res. 1987; Available from: http://www.metoffice.gov.uk/public/weather/climate/u1214qgj0.

44. Coetzee M. Key to the females of Afrotropical Anopheles mosquitoes (Diptera: Culicidae). Malar J. BioMed Central; 2020;19:1-20. Available from: https://doi.org/10.1186/s12936-020-3144-9.

45. WHO. Test procedures for insecticide resistance monitoring in malaria vector mosquitoes Second edition. World Heal Organ Geneva; 2016.

46. Asghar U, Malik MF, Anwar F, Javed A, Raza A. DNA Extraction from Insects by Using Different Techniques: A Review. Adv Entomol. 2015;03:132-8.

47. Fanello C, Santolamazza F, Della Torre A. Simultaneous identification of species and molecular forms of the Anopheles gambiae complex by PCRRFLP. Med Vet Entomol. 2002;16:461-4.

48. Abbott WS. Amethod of computing the effectiveness of insecticide. n. J Am Mosq Control Assoc. 1925;18.

49. Adugna T, Getu E, Yewhalaw D. Species diversity and distribution of Anopheles mosquitoes in Bure district, Northwestern Ethiopia. Heliyon. Elsevier Ltd; 2020;6:e05063. Available from: https://doi.org/10.1016/j.heliyon.2020.e05063.

50. Taye B, Seid M, Gindaba A. Journal of Parasitology and Vector Biology Entomological study on species composition, behavior, longevity and probability of surviving sporogony of Anopheles mosquitoes in Lare District, Ethiopia. 2017;9:137-45. Available from: http://www.academicjournals.org/JPVB.

51. Getachew D, Gebre-Michael T, Balkew M, Tekie H. Species composition, blood meal hosts and Plasmodium infection rates of Anopheles mosquitoes in Ghibe River Basin, southwestern Ethiopia. Parasite Vectors. BioMed Central; 2019;12:1-15. Available from: https://doi.org/10.1186/s13071-0193499-3.

52. Kiszewski AE, Teffera Z, Wondafrash M, Ravesi M, Pollack RJ. Ecological succession and its impact on malaria vectors and their predators in borrow pits in western Ethiopia. J Vector Ecol. 2014;39:414-23.

53. Hawaria D, Demissew A, Kibret S, Lee MC, Yewhalaw D, Yan G. Effects of environmental modification on the diversity and positivity of anopheline mosquito aquatic habitats at Arjo-Dedessa irrigation development site, Southwest Ethiopia. Infect Dis Poverty Infectious Diseases of Poverty. 2020;9:1-11.

54. Kenea O, Balkew M, Gebre-Michael T. Environmental factors associated with larval habitats of anopheline mosquitoes (diptera: Culicidae) in irrigation and major drainage areas in the middle course of the rift valley, central ethiopia. J Vector Borne Dis. 2011;48:85-92.

55. Aklilu E, Kindu M, Gebresilassie A, Yared S, Tekie H, Balkew M. Environmental factors associated with larval habitats of anopheline Mosquitoes (Diptera: Culicidae) in Metema District, Northwestern Ethiopia. J Arthropod Borne Dis. 2020;14:153-61.

56. Bamou R, Rono M, Degefa T, Midega J, Mbogo C, Ingosi P, et al. Entomological and Anthropological Factors Contributing to Persistent Malaria Transmission in Kenya, Ethiopia, and Cameroon. J Infect Dis. Oxford University Press; 2021;223:S155-70.

57. Mwangangi JM, Muturi EJ, Muriu SM, Nzovu J, Midega JT, Mbogo C. The role of Anopheles arabiensis and Anopheles coustani in indoor and outdoor malaria transmission in Taveta District, Kenya. Parasite Vectors. 2013;6:1-9.

58. Stephen A, Nicholas K, Busula AO, Webale MK, Omukunda E. Detection of Plasmodium sporozoites in Anopheles coustani s.l; a hindrance to malaria control strategies in highlands of western Keny. 2021.

59. Abdalla H, Wilding CS, Nardini L, Pignatelli P, Koekemoer LL, Ranson H, et al. Insecticide resistance in Anopheles arabiensis in Sudan: Temporal trends and underlying mechanisms. Parasite Vectors. 2014;7:1-9.

60. Verhaeghen K, Van Bortel W, Roelants P, Backeljau T, Coosemans M. Detection of the East and West African kdr mutation in Anopheles gambiae and Anopheles arabiensis from Uganda using a new assay based on FRET/Melt Curve analysis. Malar J. 2006;5:1-9.

61. Massebo F, Balkew M, Gebre-Michael T, Lindtjørn B. Blood meal origins and insecticide susceptibility of Anopheles arabiensis from Chano in SouthWest Ethiopia. Parasite Vectors. 2013;6:1-10.

62. Loonen JACM, Dery DB, Musaka BZ, Bandibabone JB, Bousema T, van Lenthe M, et al. Identification of main malaria vectors and their insecticide resistance profile in internally displaced and indigenous communities in Eastern Democratic Republic of the Congo (DRC). Malar J. 2020;19:1-10. Available from: https://doi.org/10.1186/s12936-020-03497-x.

63. PMI. Malawi Entomological Monitoring 2017 Final Report: Anopheles species abundance, sporozoite infections and insecticide resistance. 2017;130.

64. Al-Koleeby Z, El Aboudi A, Assada M, Al-Hadi M, Abdalr Ahman M, Awash A, et al. The Current Insecticide Resistance in Main Malaria Vector Anopheles arabiensis in Yemen. J Trop Med. 2020;2020.

65. Ranson H, Abdallah H, Badolo A, Guelbeogo WM, Kerah-Hinzoumbé C, Yangalbé-Kalnoné E, et al. Insecticide resistance in Anopheles gambiae: Data from the first year of a multi-country study highlight the extent of the problem. Malar J. 2009;8:1-12.

66. Deressa W, Loha E, Balkew M, Hailu A, Gari T, Kenea O, et al. Combining long-lasting insecticidal nets and indoor residual spraying for malaria prevention in Ethiopia: Study protocol for a cluster randomized controlled trial. Trials; 2016;17:1-16. Available from: http://dx.doi.org/10.1186/s13063-016-1154-2.

67. Abate A, Getu E, Wale M, Hadis M, Mekonen W. Impact of bendiocarb $80 \%$ WP indoor residual spraying on insecticide resistance status of Anopheles arabiensis. Ethiop J Sci Technol. 2020;13:215-28.

Page 9/10 
68. Mawejje HD, Wilding CS, Rippon EJ, Hughes A, Weetman D, Donnelly MJ. Insecticide resistance monitoring of field-collected anopheles gambiae s.I. populations from jinja, eastern uganda, identifies high levels of pyrethroid resistance. Med Vet Entomol. 2013;27:276-83.

69. Koffi AA, Ahoua Alou LP, Adja MA, Chandre F, Pennetier C. Insecticide resistance status of Anopheles gambiae s.s population from M'Bé: A WHOPESlabelled experimental hut station, 10 years after the political crisis in Côte d'Ivoire. Malar J. 2013;12:1-8.

70. Santolamazza F, Calzetta M, Etang J, Barrese E, Dia I, Caccone A, et al. Distribution of knock-down resistance mutations in Anopheles gambiae molecular forms in west and west-central Africa. Malar J. 2008;7:1-8.

71. Nardini L, Christian RN, Coetzer N, Ranson H, Coetzee M, Koekemoer LL. Detoxification enzymes associated with insecticide resistance in laboratory strains of Anopheles arabiensis of different geographic origin. Parasite Vectors. 2012;5:1-12.

72. Kulkarni MA, Rowland M, Alifrangis M, Mosha FW, Matowo J, Malima R, et al. Occurrence of the leucine-to-phenylalanine knockdown resistance (kdr) mutation in Anopheles arabiensis populations in Tanzania, detected by a simplified high-throughput SSOP-ELISA method. Malar J. 2006;5.

73. Kabula B, Kisinza W, Tungu P, Ndege C, Batengana B, Kollo D, et al. Co-occurrence and distribution of East (L1014S) and West (L1014F) African knockdown resistance in Anopheles gambiae sensu lato population of Tanzania. Trop Med Int Heal. 2014;19:331-41.

74. Owuor KO, Machani MG, Mukabana WR, Munga SO, Yan G, Ochomo E, et al. Insecticide resistance status of indoor and outdoor resting malaria vectors in a highland and lowland site in Western Kenya. PLoS One. 2021;16:1-15. Available from: http://dx.doi.org/10.1371/journal.pone.0240771.

75. Ochomo E, Subramaniam K, Kemei B, Rippon E, Bayoh NM, Kamau L, et al. Presence of the knockdown resistance mutation, Vgsc-1014F in Anopheles gambiae and An. arabiensis in western Kenya. Parasite Vectors; 2015;8:1-4. Available from: http://dx.doi.org/10.1186/s13071-015-1223-5.

76. Dabiré KR, Diabaté A, Namountougou M, Toé KH, Ouari A, Kengne P, et al. Distribution of pyrethroid and DDT resistance and the L1014F kdr mutation in Anopheles gambiae s.I. from Burkina Faso (West Africa). Trans R Soc Trop Med Hyg. 2009;103:1113-20.

77. Otten M, Aregawi M, Were W, Karema C, Medin A, Bekele W, et al. Initial evidence of reduction of malaria cases and deaths in Rwanda and Ethiopia due to rapid scale-up of malaria prevention and treatment. Malar J. 2009;8.

78. WHO. Achieving and maintaining universal coverage with long-lasting insecticidal nets for malaria control. Who. 2017;4. Available from: http://www.who.int/malaria/publications/atoz/who_recommendation_coverage_llin/en/.

79. Nigatu, et al. A survey for long-lasting insecticidal net coverage and use in Ethiopia Volume 3 Special issue ISSN $2709-134134$ https://ejphn.ephi.gov.et/. 2020;3:1-8.

80. Seyoum D, Speybroeck N, Duchateau L, Brandt P, Rosas-Aguirre A. Long-lasting insecticide net ownership, access and use in southwest Ethiopia: A community-based cross-sectional study. Int J Environ Res Public Health. 2017;14:1-16.

\section{Figures}

\section{Figure 1}

Map of the study area 